\title{
Building Indicators by Consensus for Common Attributes
}

\author{
Rania Al-Hammoud, Jason Grove, Andrew Milne, Mehrdad Pirnia, Derek Wright and Samanthi \\ Sooriyabandara \\ University of Waterloo \\ ralhammoud@uwaterloo.ca,jason.grove@uwaterloo.ca, ajbmilne@uwaterloo.ca, mpirnia@uwaterloo.ca, \\ derek.wright@uwaterloo.ca, samanthi.sooriyabandara@uwaterloo.ca
}

\begin{abstract}
-
To address the new process of graduate attributes (GAs) assessment as required by the Canadian Engineering Accreditation Board (CEAB), the University of Waterloo (UW) employed six Graduate Attributes Lecturers (GALs) and four Accreditation Assistants (AAs) with a key role of leading the outcomes assessment process in each of the engineering departments. The GALs work collaboratively with each other and their departments to come up with a process of outcomes assessment. The collaboration methods and techniques used by the GALs in developing shared indicators for the common GAs are proving to be highly effective, and have led to significant progress. One of these methods is a structured brainstorming sessions for developing measurable performance indicators for the common GAs.

The following paper describes in detail the collaboration methods and techniques used by the GALs and AAs to develop shared indicators for the professional skills GAs. The paper also discusses the factors that proved to be successful in the whole process as well as the challenges faced by the team.
\end{abstract}

Keywords: Brainstorming: Structured: Collaboration: CEAB: Process: Graduate Attributes, Performance Indicators, Rubrics.

\section{INTRODUCTION}

The Canadian Engineering Accreditation Board (CEAB) has changed the accreditation criteria from purely input-based assessment to include outcomes-based assessment. Programs are now to be assessed based on the graduating students' outcomes as prescribed by the $\mathrm{CEAB}$ in their Graduate Attributes (GAs) [1]. Graduate attribute assessment is an important component of the Accreditation and Continues improvement process of the Faculty of Engineering at the University of Waterloo. A team of individuals from diverse backgrounds and disciplines was employed by the University of Waterloo to champion the new graduate attributes process and initiatives introduced by the CEAB.
The University of Waterloo (UW) proactively hired six Graduate Attributes Lecturers (GALs) and four Accreditation Assistants (AAs) to lead the outcomes assessment process in each of the engineering departments. Each one of the GALs comes from a different discipline as well as the AA's have diverse work experience and are non-engineers. Together, each GAL and AA make up a departments' Graduate Attributes Team (GAT). In thirteen programs within six engineering departments, each GAT is responsible for the GA assessment for one to three programs. Within a department, the GAL and AA work collaboratively to come up with a process of outcomes assessment.

\section{REALIZING THE NEED FOR COLLABORATION}

The recruitment of GALs and AAs was done independently by each department within the University of Waterloo, Faculty of Engineering and very little cross departmental collaboration took place at initiation.

This limited interaction of GATs rapidly began to change with each GAT beginning to realize the complexity, depth and breadth of implementing GA assessments and continuous improvement $(\mathrm{CI})$ processes across their programs. Awareness of the challenges ahead initiated the GALs and the AAs to gradually reach out to each other for support.

These informal interactions amongst the GAL's and the AA's in the Faculty of Engineering, slowly started to build more confidence in moving forward with GA related tasks. In turn it was becoming clear that more formal methods of interaction, brainstorming, participation in workshops and other team building activities were necessary to collectively succeed in graduate attributes assessment and continuous improvement initiatives.

\section{FINDING COMMON GROUND}

The first workshop that the GALs initially attended helped them build comradery, which otherwise would have been difficult due to time and work constraints. This 
first workshop laid the foundation for future collaboration by giving the GALs a common language to discuss GAs and also provided a starting point for their GA work.

A decision was made for all GATs to meet on a weekly basis to discuss GA related issues. This was an excellent opportunity for GATs to bring to an open and nonjudgmental forum GA related challenges they faced within their respective departments. These meetings were also an arena to discuss/brainstorm new ideas/processes. The weekly GAT meetings continue to be extremely useful and was especially true during the first year of assessment, namely in the procurement of a survey tool. This tool has made the task of administering indirect assessments, collecting, formatting and analyzing data less cumbersome.

In addition to the weekly meetings, running a annual GA retreat has also proven to be extremely useful. The retreat brings the multidisciplinary GATs together for a period of focused and intense brainstorming sessions, which happens over a period of two days. By harnessing each other's strengths the annual retreat has helped the GATs come up with a set of common action items for the next year, established a general graduate attribute assessment process and helped re-structure the GATs meetings to one hour weekly update sessions and two hour bi-weekly working sessions.

Fueled by the above mentioned accomplishments of collaborative work. The GAT's set on a path to tackle another formidable task, which was to create common GA indicators for the seven professional skill attributes, identified by the CEAB [1]. Some of the GAs reviewed are listed in Table 1.

Table 1: Professional skills GAs

\begin{tabular}{|l|l|}
\hline \multicolumn{1}{|c|}{ GA \# } & \multicolumn{1}{c|}{ GA Description } \\
\hline GA7 & Communication Skills \\
\hline GA8 & Professionalism \\
\hline GA9 & Impact of Engineering \\
\hline GA10 & Ethics and Equity \\
\hline GA11 & Economics and Project Management \\
\hline GA12 & Life-long Learning \\
\hline
\end{tabular}

\section{STRUCTURED BRAINSTORMING}

The commitment and driving force behind creating a common set of GA indicators originated when the GATs inferred through many discussions and consultations, that a reasonable degree of consistency across the Faculty of Engineering in terms of GA indicators statements, would be preferred by the CEAB.

Achieving this consistency meant that the GATs had to identify a structured method to manage behavior and change as well as harness group strengths during the usual two hour bi-weekly GATs working sessions. Figure 1 depicts the structured brainstorming approach used by the GATs to develop common, measurable performance indicators for the professional skill GAs.

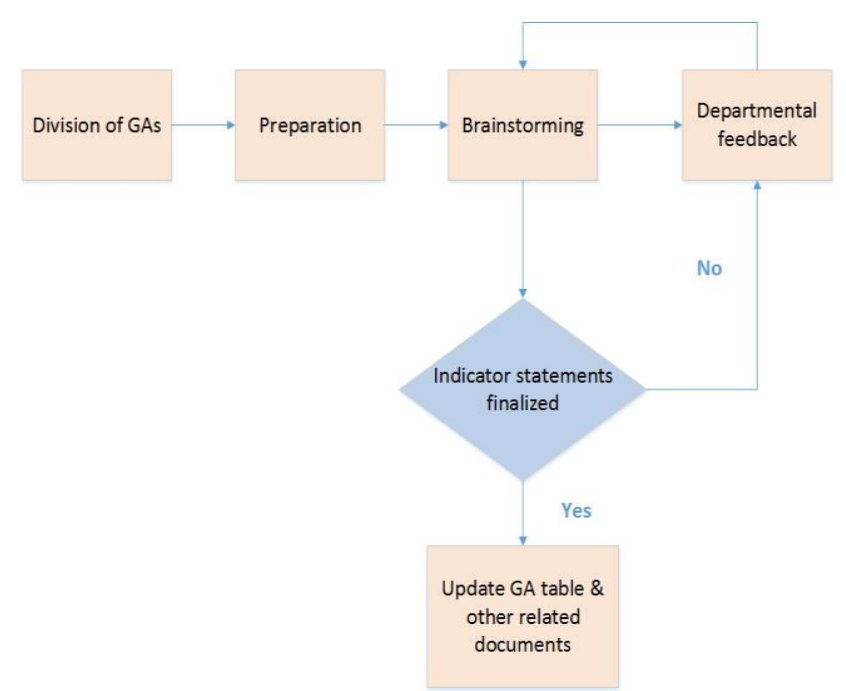

Fig 1: Structured brainstorming process

The structure of the above approach is a modified versions of the simple and effective three step change management model introduced by Kurt Lewin [5]. The first step of the brainstorming session begins with the seven professional skill GAs been divided amongst the six GATs. The GAs were assigned based on each GALs and AAs Myers-Briggs Type Indicator (MBTI) [6] exercise results from the annual GA retreat.

The delegation of work began to upset the equilibrium state in which the GA's and related indicators have been stagnating in for an extended period of time. An unfreezing of the status quo was essential in building momentum to transition in to the movement stage of the overall process.

The movement stage begins with the preparation step, in which the GATs take the GA delegated to them back to their respective departments. Then, each GAT prepares a working document in the form of a PowerPoint presentation. The presentation includes several slides that contain the following information.

- CEAB definition of the assigned GA with the main verbs and the nouns highlighted [1]

- A list of different definitions for each of the main verbs and nouns.

- List of questions for CEAB visiting team to consider, specific to courses/learning activities for the assigned GA [2]

- Indicators used in previous accreditation cycles

- Rubrics

- Any other research relevant to the GAs

The package of information described above is then presented at the bi-weekly working session by the GAL. 
In the absence of a GAL an AA would take on this responsibility. The GAL first presents the CEAB definition for the GA under discussion, while drawing everyone's attention to the main verbs and nouns. Special care is taken when choosing the most appropriate verbs to describe the level of learning assessed by referencing Blooms Taxonomy [4] shown in Fig. 2.

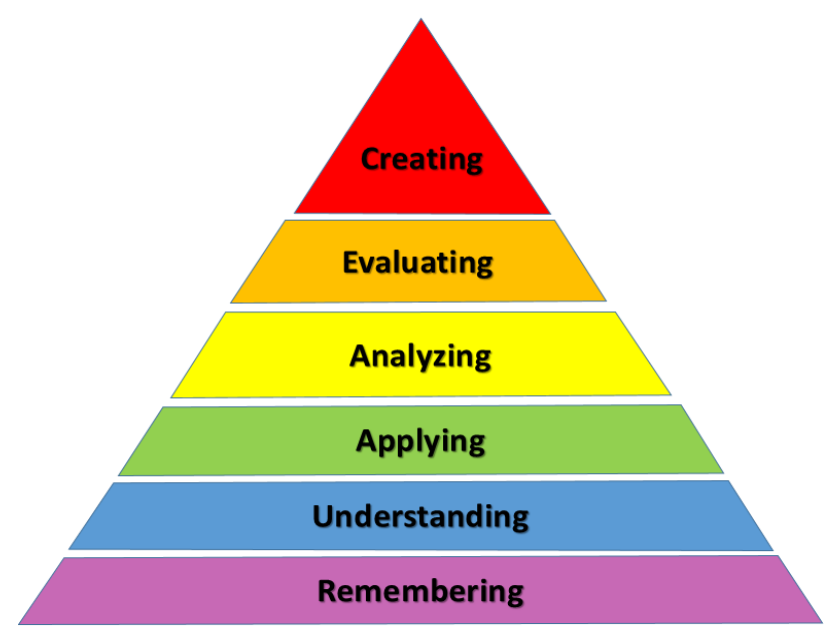

Figure 2: Blooms Taxonomy Levels

Concurrently, examples of indicator statements from previous accreditation cycles are also reviewed. Now that all GATs have a common understanding about the GA the GAL leading the presentation starts using a white board to draft new indicators. While brainstorming, the GATs keep in mind the S.M.A.R.T [3] goals frame work for the new indicators. This assures that the performance indicators are, specific, measureable, attainable, relaistic and time bound. Such structuring helps build confidence in the new indicators ability to accomplish CI objectives for GA assessments. Table 2. details how the S.M.A.R.T [3] framework helped focus new indicator building efforts,

Table 2: S.M.A.R.T Goals

\begin{tabular}{|l|l|}
\hline Specific & $\begin{array}{l}\text { Indicators should focus on } \\
\text { effective skills rather than } \\
\text { affective. }\end{array}$ \\
\hline Measureable & $\begin{array}{l}\text { Indicators should be easily } \\
\text { measurable using } \\
\text { assessments. }\end{array}$ \\
\hline Attainable & $\begin{array}{l}\text { Learning levels described } \\
\text { by the indicators should be } \\
\text { attainable by students. }\end{array}$ \\
\hline
\end{tabular}

\begin{tabular}{|l|l|}
\hline Realistic & $\begin{array}{l}\text { Does this indicator full fill } \\
\text { the GA assessment } \\
\text { requirements listed by the } \\
\text { CEAB [2]. }\end{array}$ \\
\hline Time-bound & $\begin{array}{l}\text { Can the indicators be } \\
\text { measured in a realistic time } \\
\text { frame. }\end{array}$ \\
\hline
\end{tabular}

To ensure that the performance indicators are realistic and that they meet the $\mathrm{CEAB}$ visiting teams requirements for GA assessments, the GAL alternately refers back to the list of questions for $\mathrm{CEAB}$ visiting team to consider, specific to courses/learning activities [2]. Any descriptors are removed from the indicator statements and included in the rubrics. The aim is not to have more than three performance indicators per GA, which would allow for sustainable assessment.

Once the brainstorming session is concluded each GAL takes the revised performance indicators to their departments for feedback. This feedback is then discussed at another bi-weekly working session, prior to moving on to a new GA. The discussions results in either the departmental feedback been accepted by the overall group or further revisions made to the indicator statements. In the case of the latter, the GAT responsible for the GA takes the updated indicator statements back to their respective departments for further review. The iterative process ensures that all problems related to the indicator statements is discussed and ironed out.

The final step of the structured brainstorming process begins when all the GATs come to a consensus regarding the indicator statements for a GA. Each GAT then update their GA tables and any other related documents with the refined indicator statements. Taking the GAs through a structured brainstorming process, brings each of the professional skill GAs to a new state of equilibrium. From this point on new rubrics can be developed or old rubrics revised and the most suitable means of GA assessments identified. Below is an example of performance indicators brainstormed by the GATs based on this process:

GA: Professionalism

- Articulate the roles and responsibilities of the professional engineer in society with reference to the protection of the public and its interest.

- Describe the importance of codes, standards, best practices, laws, and regulations within engineering. 
The GATs realize the dynamic nature of the GA indicators and believe that in a few years, in light of new information the GA indicator statements will have to be re-assessed. At which time the structured brainstorming process will again serve as an indispensable tool.

\section{OVERCOMING CHALLENGES}

One of the greatest challenges the GAL's and AA's faced when working together was that each individual came from different disciplines, had very different personalities, strengths and experiences. A workshop focused on managing these issues in order to improve collaboration was worked into the annual GA retreat. This workshop used the MBTI [6] to identify each team member's personality type as well as their strengths and weaknesses. A group exercise developed specially to understand which GA related tasks and initiatives match each group member's personality type, helped the overall group communicate and collaborate more constructively. Conducting a workshop based on the results of the MBTI should be credited for the efficiency and productivity that was achieved through the structured brainstorming process.

Some of the other notable items which helped the GATs work coherently was stating and working towards common goals, and identifying and tempering the male dominance within the GALs group as this group consisted of four males and two females.

Few other ongoing challenges are finding common times to meet and limiting distractions posed by other responsibilities related to the GALs and AAs roles. The GATs eventually hope to overcome these challenges as well and continue working collaboratively to successfully implement GA assessments in the Faculty of Engineering at the University of Waterloo.

\section{NEXT STEPS}

The proposed methodology has proven successful for the GATs at UW and has received approval from the respective departments for implementation. As such, the GATs would continue using the same process going forward. The points considered while brainstorming for the performance indicators will be key factors during the next stage of graduate attributes assessment which is the development of common rubrics.

\section{Acknowledgment}

The authors would like to thank the Accreditation Assistants, Claire Fermin, Colleen Mechler and Natalie Chow for their tireless support of the graduate attributes assessment process and initiatives.

\section{References}

[1] Engineering Canada, "Accreditation Criteria and Procedures," 2017. [Online]. Available: https://engineerscanada.ca/sites/default/files/accreditationcriteria-procedures-2016-final.pdf . [Accessed May 2017]

[2] Engineers Canada, "A Guide to Outcomes-based Criteria," 2015. [Online]. Available: https://engineerscanada.ca/sites/default/files/draft_program_ visitor guide v1.25.pdf . [Accessed March 2017]

[3] G.T. Doran, "There's a S.M.A.R.T. way to write management's goals and objectives," Management review (AMA Forum), vol. 70, no. 11, 35-36, 1981. Available: http://community.mis.temple.edu/mis0855002fall2015/files/ 2015/10/S.M.A.R.T-Way-Management-Review.pdf [Accessed May 2017]

[4] David R Krathwohl, “A Revision of Bloom's Taxonomy: An Overview," Theory into Practice, vol. 41, no 4, pp. 212218, 2002. Available: http://www.tandfonline.com/doi/abs/10.1207/s15430421tip4 $\underline{104 \_2}$. [Accessed May 2017]

[5] Alicia Kritsonis., "Comparison of Change Theories," International Journal of Management, Business and Administration, vol. 8, no. 1, pp. 1-7, 2005. Available: http://www.nationalforum.com/Electronic\%20Journal\%20V olumes/Kritsonis, \%20Alicia\%20Comparison\%20of\%20Cha nge\%20Theories\%20IJMBA\%20V8\%20N1\%202005.pdf . [Accessed May 2017]

[6] Terrance P O'Brien, Leonhard E Bernold and Duwane Akroyd, "Myers-Briggs Type Indicator and Academic Achievement in Engineering Education," International Journal of Engineering Education, vol. 14, no. 5, pp. 311 315, 1998. Available: https://www.ijee.ie/articles/Vol145/ijee1039.pdf . [Accessed May 2017] 